\title{
Vegetation Database of the Grassland Communities in Anatolia
}

\author{
Emin Uğurlu \& Deniz İşik
}

\begin{abstract}
In Turkey approximately 20,000 vegetation relevés do exist. However, there is no central database for Turkish vegetation relevés. We started building a vegetation database based on grassland vegetation relevés from published and unpublished data from Turkey. The database contains dune, steppic, alpine and subalpine grassland vegetation. Approximately 1,878 relevés have been entered in TURBOVEG format. Plots were georeferenced using the Google Earth plugin integrated in the TURBOVEG software. Typical header data were entered when available. Most of the relevés belong to the classes Astragalo-Brometea and DaphnoFestucetea. This report describes the available content in the Vegetation Database of the Grassland Communities in Anatolia (GIVD ID AS-TR-001).
\end{abstract}

Keywords: Astragalo-Brometea; Daphno-Festucetea; relevé; TURBOVEG; Turkey.

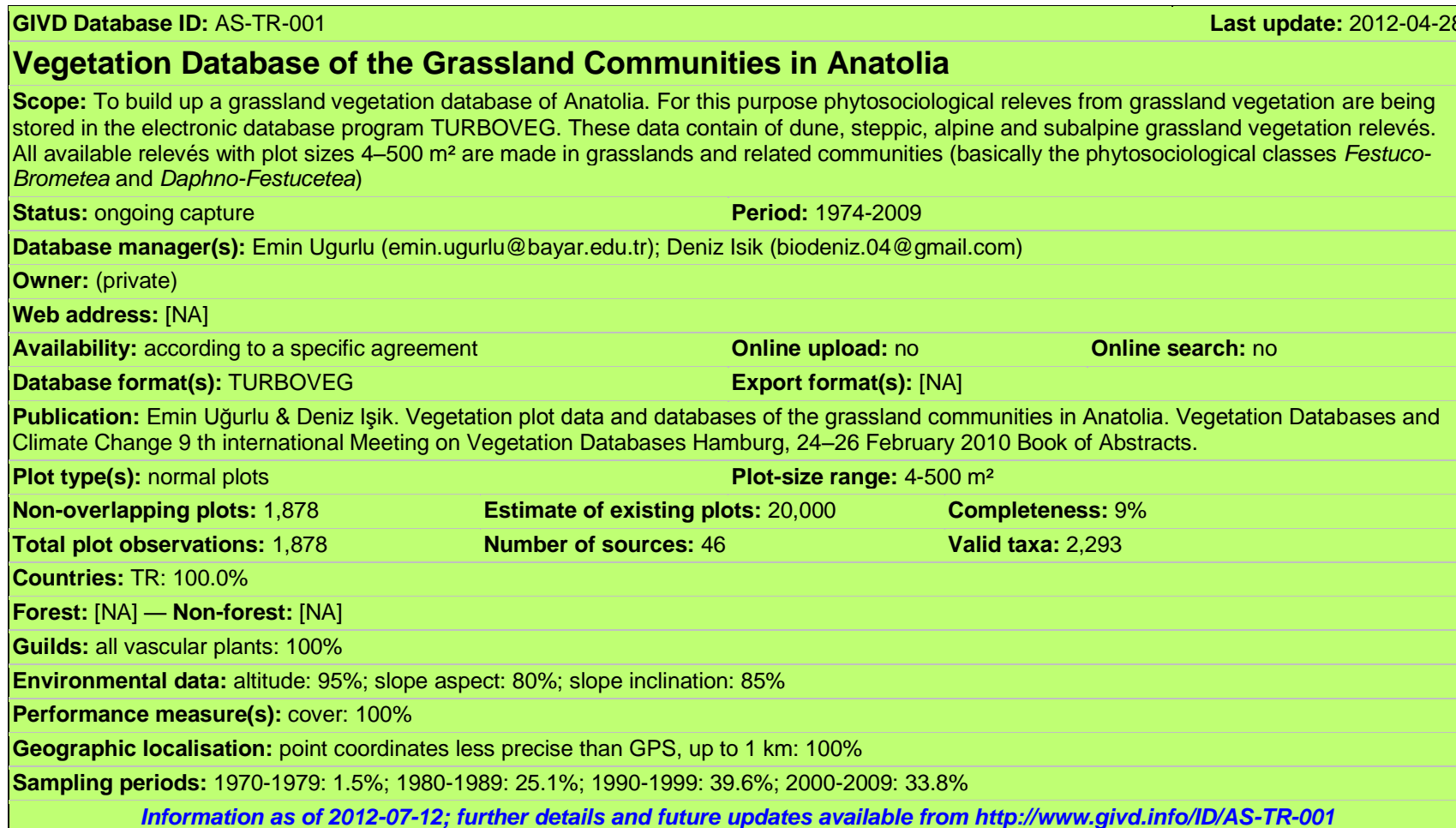

Emin Ugurlu* (emin.ugurlu@ bayar.edu.tr)

Department of Biology, Celal Bayar University Science and Art Faculty, Muradiye Campus, 45100 Manisa, TURKEY

Deniz Isik (biodeniz.04@gmail.com)

Department of Biology, Celal Bayar University, Graduate School of the Natural and Applied Science, Manisa, TURKEY

*Corresponding author 